\title{
Standardisation of thyroid cytology terminology and practice: are modifications necessary? - a narrative review
}

\author{
M. Priyanthi Kumarasinghe \\ Department of Anatomical Pathology, PathWest Laboratory Medicine, Discipline of Pathology and Laboratory Medicine, University of Western \\ Australia, QEII Medical Centre, Nedlands, Australia \\ Correspondence to: Dr. M. Priyanthi Kumarasinghe. Consultant Pathologist and Clinical Professor, Department of Anatomical Pathology, PathWest \\ Laboratory Medicine, Discipline of Pathology and Laboratory Medicine, University of Western Australia, QEII Medical Centre, J Block, Hospital \\ Avenue, Nedlands, WA 6009, Australia. Email: priyanthi.kumarasinghe@health.wa.gov.au.
}

\begin{abstract}
Universally accepted guidelines for diagnosis and management of any disease are desirable. Standardization of thyroid cytology reporting is aimed at guiding and improving clinical decision-making and management. However, socio-economic, and local factors and differences in disease prevalence and patterns require modification to suit local settings. 'One size fit all' approach is not possible for any disease diagnosis or management. The same concept is applicable in diagnosis and management of thyroid nodules. An additional special issue is the well-known high inter and intra-observer variability in the histological and cytological diagnosis of thyroid neoplasms. Despite this, thyroid cytology has a very significant influence in the management of thyroid diseases. An approach based on common principals with appropriate modifications that suits countries or continents is desirable and sustainable. The principals of TBSRTC have served as a framework for similar tiered classifications for reporting thyroid cytopathology. This article discusses globally available professional guidelines based on a common framework with appropriate modifications, with the universal aim of risk stratification of thyroid nodules.
\end{abstract}

Keywords: Thyroid cytology; terminology; modifications

Submitted May 05, 2020. Accepted for publication Aug 31, 2020.

doi: $10.21037 /$ gs-2019-catp-25

View this article at: http://dx.doi.org/10.21037/gs-2019-catp-25

\section{Introduction}

Standardisation of thyroid cytology reporting is aimed at achieving improved quality of practice and clinical decisions for optimal management. A global standard for thyroid cytology is the ideal. The Bethesda system for reporting thyroid cytology (TBSRTC) infused great enthusiasm around the world to standardize a challenging area of cytopathology (1). Prior to this many other systems have been in operation mainly in an 'ad hoc' fashion within institutions and countries (2-5). Currently, in addition to the TBSRTC developed in the USA, there are several reporting systems and guidelines recommended and adopted by professional societies in countries such as UK, Japan, Italy and Australia (5-8). Some recommendations are not restricted to reporting terminology but have either included a range of pre and post-analytical issues or aligned with parallel guidelines of related societies. These 'modifications' are linked to many variables and issues related to thyroid diseases itself and socio-economic and geographical variation.

Firstly, epidemiology of thyroid diseases differs in different geographical locations. Secondly, variable local health care delivery systems and socio-economic factors dictate judicious use of state funds and reimbursements or personal resources for investigations and management of thyroid nodules. Thirdly, there is a significant variation in interpretation and management of thyroid neoplasms across the globe. It can be argued that thyroid neoplasms are by far the best example of a neoplasm subject to a very high inter and intra observer variability $(9,10)$. In addition to epidemiological and geographical differences pre- 
analytical issues may vary according to socio economic and health economic influences. These fundamental issues have a great impact on thyroid cytology practice. Therefore, considering the variability in the epidemiology, health care delivery systems and, diagnostic and management strategies it is imperative that the modifications are necessary to suit one's requirements. We present the following article in accordance with the NARRATIVE REVIEW reporting checklist (available at http://dx.doi.org/10.21037/gs-2019catp-25).

\section{Methods and discussion}

\section{Global trends of thyroid diseases and the influence by Asia}

According to the GLOBOCAN estimates, $48 \%$ of all new thyroid cancer cases are diagnosed in Asia with an incidence of $60 \%$ and prevalence of $57.4 \%$ (11). Among Asian countries Japan and Korea have made a great contribution to the international community with evidence-based experience of diagnosing and managing thyroid tumours (12-14). Thyroid malignancies represent approximately $5 \%$ of all thyroid nodules and malignancies presenting as a diffuse enlargement is extremely rare $(15,16)$. Equally, about $60 \%$ of thyroid nodules show benign cytology in clinical practice (1-8). An allowance should be made to these figures depending on the geographical location and associated environment factors. If hotspots, such as locations and countries with increased exposure to radiation and iodine deficiency are excluded above figures may be generalized globally. It is noteworthy that benign and malignant cytological categories are comparable in incidence and do not appear to provoke significant controversy in terms of categorisation or diagnostic criteria in a global setting (1-8). When malignant and benign diagnoses are excluded approximately $35 \%$ of cytological diagnosis of all thyroid nodules fall into an 'inconclusive/uncertain group' (1-8). This uncertain group that includes non-neoplastic and benign neoplastic lesions as well as a proportion of differentiated malignant neoplasms is the central focus that needs guidance in terms of sampling, interpretation, terminology and management. The risk of malignancy $(\mathrm{ROM})$ and risk of neoplasms ( $\mathrm{RON})$ within this group and prognosis of these neoplasms as well as the management appear variable (12,17-19). Although those thyroid lesions that are suspicious for malignancy could be included in the uncertain group they should be regarded with a different emphasis to the above (1-8).
Compared to the Western experience, Asian studies have shown low resection rates and high ROM in the cytologically uncertain group of thyroid nodules $(13,20,21)$. This is believed to be due to the conservative management approach by Asian clinicians (21). However, national mortality rates are comparable in countries such as United States, Korea, Israel, Canada, France, Italy and Australia $(22,23)$.

There is also an argument against over sampling leading to detection of indolent lesions referred to as incidentalomas (24). The overuse of radiology to detect such lesions followed by a diagnosis of malignancy, most commonly papillary thyroid carcinoma often results in surgery in spite of standard guidelines for radiological sampling of thyroid nodules (25).

It is obvious that the ROM of a cytological category of a thyroid nodule cannot be equated to risk of clinically significant disease $(14,26)$. There is hardly any other human malignancy than thyroid that has proven to have distinctly variable outcomes (27). Among the $5 \%$ of malignant thyroid nodules, clinically aggressive thyroid malignancies are anaplastic and poorly differentiated carcinoma, some angioinvasive and widely invasive follicular carcinomas, a proportion of medullary carcinomas, aggressive lymphomas and rare metastases, in addition to a small proportion of aggressive papillary thyroid carcinomas. Of these, widely invasive and angioinvasive follicular carcinomas and poorly differentiated carcinomas are often categorised cytologically as suggestive/suspicious of follicular neoplasms or a related category based on the "classical repetitive microfollicular pattern" (1-8). Hemithyroidectomy is offered to these lesions in many countries. The Japanese approach includes sub-categorisation of 'follicular neoplasms' into low and high-risk lesions on cytomorphology with conservative management offered for low risk follicular patterned neoplasms (6). Apart from the above group, the other clinically significant malignancies are often categorized as suspicious or malignant followed by appropriate management. It is the general impression that over diagnosis and overtreatment of thyroid neoplasms is a larger issue than underdiagnoses $(21,28-32)$. It is also interesting to note the geographic variability of prevalence of thyroid cancer over diagnosis and malpractice claims $(33,34)$.

\section{Recent WHO recommendations}

A notable change in the practice of thyroid neoplasms was the recent introduction of the tumour type referred 
to as non-invasive follicular thyroid neoplasm with papillary-like nuclear features (NIFTP) by World Health Organization (WHO) for those tumours previously termed encapsulated follicular variant of papillary thyroid 'carcinoma' (EFVPTC) (35). This remarkable change to the approach of diagnosis of follicular patterned thyroid neoplasms further supports the historic lack of robust histological diagnostic criteria for low grade, differentiated follicular patterned neoplasms (9,36-38). Over time many studies have highlighted the variability in histological diagnosis, cytological categorization and management for EFVPTC with significant geographical differences (37-42). Recognition of RAS and BRAF molecular pathways of thyroid tumorigenesis has cemented the need for new approaches in both histological and cytological diagnosis (43). In this regard it is interesting to note the assertion by some Japanese pathologists to recognize RAS and BRAF like nuclear features in cytology (44). Following this change by WHO, a substantial amount of evidence emerged with regards to the variable prevalence of NIFTP lesions globally. It appears that the prevalence is much less in Asia than in the West (45). An equally important realization is the variability of impact of this change on ROM and RON of thyroid cytology categories (39-42). These observations further confirm the necessity for modifications for pathological interpretation, recommendations and management in this group of thyroid nodules. A modified approach based on scientific principles and that accommodates these variabilities would not have a negative impact but allows flexibility for patient management in different settings.

Ironically there are groups that believe overzealous dependence on guidelines may even limit one's independent approach to diagnosis and management (46).

\section{Molecular testing in thyroid cytology}

Molecular testing with the hope of improving the prediction of ROM in the uncertain group has been recommended by TBSTCR $(1,47)$. The economic and logistical issues of this approach need to be re-visited as evidence appears variable on its acceptance, value and cost effectiveness (48). Additionally, positive predictive value of molecular testing for inconclusive nodules has reduced with the recent WHO revision of encapsulated FVPTC as NIFTP $(49,50)$. However, the value of BRAF mutation testing to confirm a diagnosis of papillary thyroid carcinoma by upgrading the suspicious category appears to be universally accepted (51-53).

\section{FNA collection and preparation of material}

Both direct and ultrasound guided aspirations with and without rapid on-site evaluation (ROSE) is practiced globally depending on the available resources $(54,55)$. Liquid base cytology (LBC) is used in some centers. $\mathrm{LBC}$ techniques may be useful if material is collected by inexperienced, in particular non-pathology staff with no exposure to cytology techniques. Important diagnostic cytological features are often lost in LBC preparations and cytology staff needs re-training, hence the technology is mandated in many countries $(56,57)$.

Considering the variety of issues discussed above it is apparent that strict global standardisation is hard to achieve and modifications based on a common framework is more realistic. Table 1 shows a general overview of well-known systems across the globe.

\section{The Bethesda system for reporting thyroid cytology (TBSRTC, USA)}

The revised version that was published in 2017 , focused on guidelines for management based on the evidence that was gathered following its inception in 2008 (1). As expected, there was emphasis on reclassification of non-invasive (encapsulated and/or circumscribed) follicular variant of papillary thyroid carcinoma by the $\mathrm{WHO}$ as non-invasive follicular thyroid neoplasm with papillary-like nuclear features (NIFTP). In order to eliminate NIFTPs from the malignant category the revised version recommends that a suspected papillary thyroid carcinoma with an exclusive follicular architecture, especially one that lacks intranuclear cytoplasmic pseudoinclusions and psammoma bodies to be interpreted as suspicious of malignancy rather than malignant. It is also acknowledged that follicular neoplasms, FVPTCs and NIFTPs cannot be accurately distinguished by cytology alone due to their overlapping cytomorphological features as opposed to PTC signified by the classical cytoarchitecture. Classical papillary thyroid carcinoma is characterized by monolayered sheets and papillary structures while the variants show features. The fact that NIFTPs were categorised as encapsulated FVPTC (thereby as a malignancy) prior to $\mathrm{WHO}$ revision would explain at least in part the higher rate of ROMs reported in some studies. Current literature suggests that the rates of FVPTC and NIFTP appear significantly low in Asian practice compared to the West $(37,41,42)$. Implied risks 
Table 1 A general comparison of global systems

\begin{tabular}{|c|c|c|c|c|c|}
\hline Categories & USA [2008] & United Kingdom [2011] & Italy [2014] & Australia [2014] & Japan [2013] \\
\hline 2 & Benign & Thy2. Non-neoplastic & $\begin{array}{l}\text { TIR2. Non-malignant/ } \\
\text { benign }\end{array}$ & Benign & 2. Normal benign \\
\hline 4 & $\begin{array}{l}\text { Follicular neoplasm suspicious } \\
\text { for follicular neoplasm } \\
\text { ((FN/SFN) }\end{array}$ & $\begin{array}{l}\text { Thy 3f. Neoplastic } \\
\text { possible- Suggesting a } \\
\text { follicular neoplasm }\end{array}$ & $\begin{array}{l}\text { TIR3b. High risk } \\
\text { indeterminate lesion }\end{array}$ & $\begin{array}{l}\text { Suggestive of } \\
\text { follicular neoplasm }\end{array}$ & $\begin{array}{l}\text { 3b. Indeterminate- } \\
\text { others }\end{array}$ \\
\hline 6 & Malignant & Thy 5. Malignant & TIR5. Malignant & Malignant & 5. Malignancy \\
\hline
\end{tabular}

of malignancy have been revised in the second edition of TBSRTC as a response to the WHO revision. ROM was revised as $6-18 \%$ from $10-30 \%, 10-40 \%$ from $25-40 \%$ and $45-60 \%$ from $50-75 \%$ for categories 3,4 and 5 respectively reflecting an overall reduction (58). The management recommendations in the TBSRTC system includes molecular testing as an adjunct to the cytopathological examination for the inconclusive group of nodules. However, positive predictive value of molecular testing has reduced with the introduction of NIFTP $(49,50)$.

\section{The British thyroid Association-RCPath system}

This system that was introduced in 2002 was revised in 2009 (see Table 1). More recently the cytology terminology with additional comments was embedded in management recommendations by the British thyroid Association guidelines for management of thyroid cancer 2014 (5). Multidisciplinary approach is emphasised in the British system. Effectively, the system has six categories similar to the others. The differences include subdividing non-diagnostic categories to cystic and non-cystic lesions and the most challenging uncertain group placed under the umbrella term of "neoplasm possible". Within this umbrella category those with atypia and others suggesting a follicular neoplasm are separated.

\section{The Japanese system}

Even within Japan, there are a few related systems used for cytology reporting and management of thyroid nodules. They include General Rules for the Description of Thyroid Cancer (GRDTC) published by the Japanese Society of Thyroid Surgery (JSTS) in 2005 and updated in 2016, and the national reporting system (the Japanese system) for thyroid FNA cytology published by the Japan thyroid Association in 2013 (6,21). The Japanese system was included in the clinical guidelines published by the Japan Thyroid Association (JTA) in 2013. The Japanese system was adapted from Toriya's diagnostic system characterized by two or three sub classifications of the indeterminate (uncertain) group (2). Japanese system emphasised sub classification of the two categories within the uncertain group based on cytomorphology and on the molecular basis of RAS and BRAF driven pathways. Even within Japan there is variability in using the systems. Although GRDTC widely used, some high-volume thyroid surgery centers prefer the Japanese system (see Table 1) as many patients with a diagnosis of follicular neoplasm do not undergo diagnostic thyroidectomy.

\section{The Italian system}

The Italian Society for Anatomical Pathology and Cytopathology-International Academy of Pathology in conjunction with clinical groups formulated a system in 2007 followed by a revision in 2014 (7). There are again six categories with the uncertain group divided into low risk indeterminate and high-risk indeterminate lesions (see 
Table 2 Risk of malignancy in 'inconclusive categories' in Australia (59-62)

\begin{tabular}{lc}
\hline Category & Risk of malignancy \\
\hline 3 & $9.3-13 \%$ \\
4 & $15.3-24.4 \%$ \\
5 & $79-84.7 \%$ \\
\hline
\end{tabular}

Table 1). The lower risk lesions are offered repeat FNA and or clinical follow-up and the high-risk lesions are offered surgery. One important difference to other systems is that nodules with repeated inadequate cytology samples ae recommended to be sampled by core needle biopsy and LBC.

\section{The Australasian reporting guidelines}

Historically, cytological categories have been used in Australia for thyroid cytology reporting $(3,59)$. The Australasian reporting guidelines are based on the general framework of the 6 categories of the Bethesda system with a modified approach. Modifications were necessary to streamline standardisation within the country while maintaining well established and "time tested" systems that were operational previously, yet embracing positive aspects of the TBSRTC. First edition was completed and published in 2014 and a subsequent review was published in "Pathology" (8). The second edition was published in 2019 incorporating updated WHO terminology for EFVPTCs and updates on molecular basis of thyroid tumours (60). The opinions were based on local experiences and local data including follow-up studies in two states in Australia $(59,61)$. The study done in Western Australia and published in 2010 used 6 categories and mirrored the TBSRTC system published in 2010 and the study done in New South Wales subsequently used the TBSRTC system, enabling easy comparison of the data $(59,61)$. However it should be noted that the numbers in our studies are relatively small compared to those of Asian series due to the lower prevalence of thyroid neoplasms locally. In Australian guidelines the use of the term 'atypia' is discouraged in the general diagnostic category in the uncertain group with low ROM (equivalent to Bethesda category 3) to avoid confusion among clinicians that may result in overtreatment. The term 'Indeterminate' is recommended in the Australasian guidelines for the equivalent of TSBRTC category 3. Most cases in this category would have a benign follow up as shown in the above-mentioned studies in
Australia that showed a malignancy rate of only $13 \%$ and $9.3 \%(59,61)$ (Table 2). A detailed analysis of the West Australian cohort showed a minimum of $33 \%$ of PTCs in this category were "follicular variants of papillary thyroid carcinoma", only 22\% were classical PTCs and others were PTCs, unclassified (unpublished data). As such implied ROM in this category with the recent revision of EFVPTC as NIFTP may be even low.

The use of the term 'suspicious of follicular neoplasms' is not recommended for category 4 (those lesions that show a strong likelihood of a follicular neoplasm) as only $15-24 \%$ of nodules were malignant $(59,60)$, hence the word suspicious could be misleading. The spectrum of entities ranges from benign to malignant and include cellular hyperplastic nodule, follicular adenoma, follicular carcinoma, Hürthle cell neoplasm and follicular variant of papillary thyroid carcinoma (FVPTC). Lesions that are highly suggestive of a neoplasm with minimal, subtle nuclear features are often included in this category. Australian experiences suggest a high ROM in the suspicious for malignancy category (category 5) 79\% and $83 \%$ respectively in the 2 studies $(61,62)$. We also recommend BRAF mutation testing to confirm papillary thyroid carcinoma in those in those nodules that are otherwise categorised as suspicious for PTC (62).

It is important to note the ROMs reported in both studies were closer to those projected in revised TBSRTC based on WHO 2017 revision of NIFTPs. This observation reflects high quality cytology practices as well as higher thresholds for diagnosis of FVPTC in Australia. Australasian practice recommends emphasis on the presence of monolayered sheets or papillary formations to represent papillary nature of papillary thyroid carcinoma with the expectation to avoid misdiagnosis of NIFTPs as malignant (60). The expert committee that formulated guidelines is of the opinion that in Australasia, the prevalence of NIFTP (former EFVPTC) is not as high as is reported in the United States.

\section{Conclusions}

In conclusion, the implied ROM for a cytological diagnosis of a thyroid nodule essentially guides the clinical decision for definitive surgical management or other aggressive types of treatment. Therefore, the most important aim of performing thyroid fine-needle aspiration is for the accurate diagnosis of malignant neoplasms and appropriate risk stratification of uncertain nodules. However, it is apparent that there are 
significant differences in both cytological and histological diagnosis of thyroid neoplasms worldwide due to medicosocial and geographic variations. Therefore, a globally accepted strict standardised approach does not appear feasible. A common framework of risk categorisation based on cytological features of a thyroid nodule that would encompass local factors appears to be a satisfactorily approach.

\section{Acknowledgments}

Thyroid cytopathology community in Australasia. Funding: None.

\section{Footnote}

Provenance and Peer Review: This article was commissioned by the Guest Editor (Kennichi Kakudo) for the series "Asian and Western Practice in Thyroid Pathology: Similarities and Differences" published in Gland Surgery. The article has undergone external peer review.

Reporting Checklist: The author has completed the NARRATIVE REVIEW reporting checklist. Available at http://dx.doi.org/10.21037/gs-2019-catp-25

Conflicts of Interest: The author has completed the ICMJE uniform disclosure form (available at http://dx.doi. org/10.21037/gs-2019-catp-25). The series "Asian and Western Practice in Thyroid Pathology: Similarities and Differences" was commissioned by the editorial office without any funding or sponsorship. The author has no other conflicts of interest to declare.

Ethical Statement: The author is accountable for all aspects of the work in ensuring that questions related to the accuracy or integrity of any part of the work are appropriately investigated and resolved.

Open Access Statement: This is an Open Access article distributed in accordance with the Creative Commons Attribution-NonCommercial-NoDerivs 4.0 International License (CC BY-NC-ND 4.0), which permits the noncommercial replication and distribution of the article with the strict proviso that no changes or edits are made and the original work is properly cited (including links to both the formal publication through the relevant DOI and the license). See: https://creativecommons.org/licenses/by-nc-nd/4.0/.

\section{References}

1. Cibas ES, Ali SZ. The 2017 Bethesda System for Reporting Thyroid Cytopathology. J Am Soc Cytopathol 2017;6:217-22.

2. Toriya K. Cytological aspiration biopsy of goiters, especially with reference to their histological and cytological examinations. J Jpn Soc Clin Cytol 1972;11:101-14.

3. Orell SR, Philips J. Broadsheet number 57: problems in fine needle biopsy of the thyroid. Pathology 2000;32:191-8.

4. The Papanicolaou Society of Cytopathology Task Force on Standards for Practice. Guidelines of the Papanicolaou Society of Cytopathology for fine needle aspiration procedure and reporting. Diagn Cytopathol 1997;17:239-47.

5. Cross P. Chndra A, Giles T, et al. Guidance on the reporting of thyroid cytology specimens. London: Royal College of pathologists, 2016.

6. Kakudo K, Kameyama K, Miyauchi A. History of thyroid cytology in Japan and reporting system recommended by the Japan Thyroid Association. J Basic Clin Med 2013;2:10-5.

7. Nardi F, Basolo F, Crescenzi A, et al. Italian consensus for the classification and reporting of thyroid cytology. J Endocrinol Invest 2014;37:593-9.

8. Kumarasinghe MP, Cummings MC, Raymond W, et al. Approach to thyroid cytology: rationale for standardisation. Pathology 2015;47:285-8.

9. Hirokawa M, Carney JA, Goellner JR, et al. Observer variation of encapsulated follicular lesions of the thyroid gland.Am J Surg Pathol 2002;26:1508-14.

10. Elsheikh TM, Asa SL, Chan JK, et al. Interobserver and intraobserver variation among experts in the diagnosis of thyroid follicular lesions with borderline nuclear features of papillary carcinoma. Am J Clin Pathol 2008;130:736-44.

11. Ferlay J, Soerjomataram I, Ervik M, et al. GLOBOCAN 2012 v1.0, Cancer incidence and mortality worldwide: IARC CancerBase No. 11 [Internet]. Lyon: International Agency for Research on Cancer, 2013 [cited 2016 Oct 18]. Available Online: http://globocan.iarc.fr.

12. Japan Thyroid Association. Guidelines for clinical practice for the management of thyroid nodules in Japan 2013. Tokyo: Nankodo Co., Ltd., 2013.

13. Ahn HS, Kim HJ, Welch HG. Korea's thyroid-cancer "epidemic": screening and overdiagnosis. N Engl J Med 2014;371:1765-7. 
14. Ito $\mathrm{Y}$, Uruno T, Nakano K, et al. An observation trial without surgical treatment in patients with papillary microcarcinoma of the thyroid. Thyroid 2003;13:381-7.

15. Tan GH, Gharib H, Reading CC. Solitary thyroid nodule. Comparison between palpation and ultrasonography. Arch Intern Med 1995;155:2418-23.

16. Mackenzie EJ, Mortimer RH. Thyroid nodules and thyroid cancer. Medical Journal of Australia 2004;180:242-7.

17. Vuong HG, Ngo HTT, Bychkov A, et al. Differences in surgical resection rate and risk of malignancy in thyroid cytopathology practice between Western and Asian countries: A systematic review and meta-analysis. Cancer Cytopathol 2020;128:238-49.

18. Gan TRX, Nga ME, Lum JHY, et al. Thyroid cytologynuclear versus architectural atypia within the 'Atypia of undetermined significance/follicular lesion of undetermined significance' Bethesda category have significantly different rates of malignancy. Cancer Cytopathol 2017;125:245-56.

19. Thewjitcharoen Y, Butadej S, Nakasatien S, et al. Incidence and malignancy rates classified by The Bethesda System for Reporting Thyroid Cytopathology (TBSRTC) - An 8-year tertiary center experience in Thailand. J Clin Transl Endocrinol 2018;16:100175.

20. Kakudo K. How to handle borderline/precursor thyroid tumors in management of patients with thyroid nodules. Gland Surg 2018;7:S8-S18.

21. Kakudo K, Higuchi M, Hirokawa M, et al. Thyroid FNA cytology in Asian practice-Active surveillance for indeterminate thyroid nodules reduces overtreatment of thyroid carcinoma. Cytopathology 2017;28:455-66.

22. Joannie Lortet-Tieulent, Silvia Franceschi, Luigino Dal Maso, et al.. Thyroid cancer "epidemic" also occurs in low- and middle income countries. Int J Cancer 2019;144:2082-7.

23. AIHW (Australian Institute of Health and Welfare). Australian Cancer Incidence and Mortality (ACIM) books. Available online: http://www.aihw.gov.au/acim-books/. Accessed: 3rd Dec 2012.

24. Brito JP, Davies L, Zeballos-Palacios C, et al. Papillary lesions of indolent course: reducing the overdiagnosis of indolent papillary thyroid cancer and unnecessary treatment. Future Oncol 2014;10:1-4.

25. Haugen BR, Alexander EK, Keith C, et al. 2015 American Thyroid Association Management Guidelines for Adult Patients with Thyroid Nodules and Differentiated Thyroid Cancer The American Thyroid Association Guidelines
Task Force on Thyroid Nodules and Differentiated Thyroid Cancer THYROID Volume 26, Number 1, 2016.

26. Leboulleux S, Tuttle RM, Pacini F, et al. Papillary thyroid microcarcinoma: time to shift from surgery to active surveillance? Lancet Diabetes Endocrinol 2016;4:933-42.

27. Bo YC, Hoo SC, Young JP, et al. Changes in the clinicopathological characteristics and outcomes of thyroid cancer in Korea over the past 4 decades. Thyroid 2000;23:797-804.

28. Vickie Schandig. All diagnosis of thyroid cancer. Is this not an ethical issue for pathologists as well as radiologists and clinicians. Arch Pathol Lab Med 2019;142:1018-20.

29. Renshaw AA, Gould EW. In response to "Overdiagnosis of thyroid cancer: is this not an ethical issue for pathologists as well as radiologists and clinicians [letter]?" Arch Pathol Lab Med 2019;143:782-3.

30. Shah V, Scott-Coombes D, Varma M. Cancer overdiagnosis: pathologists in the dock. Arch Pathol Lab Med 2019;143:781.

31. Jegerlehner S, Bulliard JL, Aujesky D, et al. Overdiagnosis and overtreatment of thyroid cancer: A population-based temporal trend study. PLoS One 2017;12:e0179387.

32. Glasziou PP, Jones MA, Pathirana T, et al Estimating the magnitude of cancer over-diagnosis in Australia. Med J Aust 2020;212:163-8.

33. Warrick J, Lengerich E. Thyroid cancer overdiagnosis and malpractice climate [letter]. Arch Pathol Lab Med 2019;143:414-5.

34. Kakudo K, Bychkov A, Abelardo A, et al. Malpractice Climate Is a Key Difference in Thyroid Pathology Practice Between North America and the Rest of the World. Arch Pathol Lab Med 2019;143:1171.

35. WHO (World Health Organization) (2017). WHO classification of tumours of endocrine organs (4th edition). Lloyd RV, Osamura R, Kloppel G, Rosai J. Lyon: IARC Press, 2017.

36. Cipriani NA, Nagar S, Kaplan S, et al. Follicular thyroid carcinoma: How have histological diagnosis changed in the last half century and what are not prognostic implications? Thyroid 2015;25:1209-16.

37. Liu Z, Bychkov A, Jung CK, et al. Interobserver and intraobserver variation in the morphological evaluation of noninvasive follicular thyroid neoplasm with papillary-like nuclear features in Asian practice. Pathol Int 2019;69:202-10.

38. Seethala RR, Baloch ZW, Barletta JA. Noninvasive follicular thyroid neoplasm with papillary-like nuclear features: a review for pathologists. Mod Pathol 
2018;31:39-55.

39. Strickland KC, Howitt BE, Marqusee E, et al. The Impact of Noninvasive Follicular Variant of Papillary Thyroid Carcinoma on Rates of Malignancy for FineNeedle Aspiration Diagnostic Categories. Thyroid 2015;25:987-92.

40. Vuong HG, Tran TTK, Bychkov A, et al. Clinical impact of non-invasive follicular thyroid neoplasm with papillarylike nuclear features on the risk of malignancy in the Bethesda system for reporting thyroid cytopathology: a meta-analysis of 14,153 resected thyroid nodules. Endocr Pract 2019;25:491-502.

41. Bychkov A, Keelawat S, Agarwal S, et al. Impact of noninvasive follicular thyroid neoplasm with papillary-like nuclear features on the Bethesda system for reporting thyroid cytopathology: a multi-institutional study in five Asian countries. Pathology 2018;50:411-7.

42. Faquin WC, Wong LQ, Afrogheh AH, et al. Impact of reclassifying noninvasive follicular variant of papillary thyroid carcinoma on the risk of malignancy in The Bethesda System for Reporting Thyroid Cytopathology. Cancer Cytopathol 2016;124:181-7.

43. Giordano TJ, Kuick R, Thomas DG, et al. Molecular classification of papillary thyroid carcinoma: distinct BRAF, RAS, and RET/PTC mutation-specific gene expression profiles discovered by DNA microarray analysis. Oncogene 2005;24:6646-56.

44. Kakudo K, Pusztaszeri MP, Bongiovanni M. Factors impact in thyroid fine needle aspiration cytology and algorithm for cytologyical diagnosis in the Japanese system for reporting FNA cytology. In: Kakudo K. editor. Thyroid FNA cytology. Springer International Publishing, 2019.

45. Bychkov A, Chan KJ, Zhiyan L, et al. Non-invasive follicular thyroid neoplasm with papillary-like nuclear features in Asian practice: Perspective is a surgical pathology and cytopathology. Endocr Pathol 2018;29:276-88.

46. Schnadig VJ. Overdiagnosis of thyroid cancer: is this not an ethical issue for pathologists as well as radiologists and clinicians? Arch Pathol Lab Med 2018;142:1018-20.

47. Alexander EK, Kennedy GC, Baloch ZW, et al. Preoperative Diagnosis of Benign Thyroid Nodules with Indeterminate Cytology. N Engl J Med 2012;367:705-15.

48. Elsheikh TM, Rossi ED. Utilisation of molecular testing in thyroid cytology. Pathology Case Reviews 2014;19:3-7s.

49. Hang JF, Westra WH, Cooper DS, et al. The impact of noninvasive follicular thyroid neoplasm with papillary-like nuclear features on the performance of the Afirma gene expression classifier. Cancer Cytopathol 2017;125:683-91.

50. Valderrabano P, Khazai L, Leon ME, et al. Evaluation of ThyroSeq v2 performance in thyroid nodules with indeterminate cytology. Endocr Relat Cancer 2017;24:127-36.

51. Leslie C, Grieu-Iacopetta F, Richter A, et al. BRAF p.Val600Glu (V600E) mutation detection in thyroid fine needle aspiration cell block samples: a feasibility study. Pathology 2015;47:432-8.

52. Kang G, Cho EY, Shin JH, et al. Role of BRAFV600E mutation analysis and second cytologic review of fine needle aspiration for evaluating thyroid nodule. Cancer Cytopathol 2012;120:44-51

53. Ohori NP, Singhal R, Nikiforova MN, et al. BRAF mutation detection in indeterminate thyroid cytology specimens: underlying cytologic, molecular, and pathologic characteristics of papillary thyroid carcinoma. Cancer Cytopathol 2013;121:197-205.

54. Olson MT, Armanda D, Tatsas AD, et al. Cytotechnologistattended on-site adequacy evaluation of thyroid fine needle aspiration. Comparison with cytopathologists and correlation with the final interpretation. Am J Clin Pathol 2012;138:90-5.

55. Burlingame OO, Kesse KO, Silverman SG, et al. Onsite adequacy evaluations performed by cytotechnologists correlation with final interpretations of 5241 imageguided fine-needle aspiration biopsies. Cancer Cytopathol 2012;120:177-84.

56. Saleh H, Bassily N, Hammoud MJ. Utility of a liquidbased, monolayer preparation in the evaluation of thyroid lesions by fine needle aspiration biopsy: comparison with the conventional smear method. Acta Cytol 2009;53:130-6.

57. Fischer AH, Clayton AC, Bentz JS, et al. Performance differences between conventional smears and liquid-based preparations of thyroid fine-needle aspiration samples: analysis of 47,076 responses in the College of American Pathologists Interlaboratory Comparison Program in Non-Gynecologic Cytology. Arch Pathol Lab Med 2013;137:26-31.

58. Ali S, Cibas ES. editors. The Bethesda System for Reporting Thyroid Cytopathology.Definitions, Criteria and Explanatory Notes. 2nd Edition, Springer, 2017.

59. Nga ME, Kumarasinghe MP, Tie B, et al. Experience with standardized thyroid fine-needle aspiration reporting categories: follow-up data from 529 cases with "indeterminate" or "atypical" reports. Cancer Cytopathol 
2010;118:423-33.

60. Royal College of Pathologists of Australasia (RCPA). RCPA Cancer. Protocols. Available online: https://www. rcpa.edu.au/Library/Practising-Pathology/StructuredPathology-Reporting-of-Cancer/Cancer-Protocols

61. Sarkis LM, Norlen O, Aniss A, et al. The Australian experience with the Bethesda classification system for thyroid fine needle aspiration biopsies. Pathology

Cite this article as: Kumarasinghe MP. Standardisation of thyroid cytology terminology and practice: are modifications necessary? —a narrative review. Gland Surg 2020;9(5):1639-1647. doi: $10.21037 /$ gs-2019-catp-25
2014;46:592-5.

62. Clinical significance of Malignant and Suspicious categories in thyroid FNA cytology. Predictive value analysis during 2004-2013 from a single laboratory. Australasian division of the International Academy of pathology. Poster presentation IAP-Australasian division 2016. 